\title{
Assessing the cost of fuel reduction treatments: A critical review
}

\author{
Bob Rummer* \\ U.S. Forest Service, 520 Devall Drive, Auburn, AL 36849, United States
}

\begin{abstract}
The basic costs of the operations for implementing fuel reduction treatments are used to evaluate treatment effectiveness, select among alternatives, estimate total project costs, and build national program strategies. However, a review of the literature indicates that there is questionable basis for many of the general estimates used to date. Different approaches to estimating cost have been used. Four methods are reviewed with discussion of the appropriate applications to fuel reduction cost analysis. Critical gaps identified in the understanding of operations costs include business overhead, repair and maintenance reserves, and estimates of the cost of risk. Future analyses of fuel treatments should be cautious in extrapolating cost numbers from the existing literature.
\end{abstract}

Published by Elsevier B.V.

Keywords: Costs; Forest operations; Mechanical treatment; Thinning

\section{Introduction}

Forest resource management in the U.S. is facing a major evolution of purpose. For many years, resource management focused activity on acres that were deemed "suitable" for management and relegated the vast remainder of the forest to the consequences of natural processes. In large part this reflected consideration of narrowly defined economic and ecological feasibility. Economic feasibility generally meant direct tangible returns were greater than operational costs, while ecological feasibility tended to be determined by avoidance of immediate anthropogenic impacts. Environmentally sensitive areas were seldom treated because the costs of light-on-the-land operations were often greater than potential returns.

In fact, the impact of neglecting management on forest lands in general has been borne home in dramatic fashion. Ecological degradation of fire-dependent forest types, primarily a result of effective fire suppression, has led to increased wildfire risk and adverse habitat changes. The National Fire Plan evolved from the recognition that active management is needed to address the ecological condition of fire-dependent forest types. More recently other threats such as the spread of invasive species

\footnotetext{
* Corresponding author. Tel.: +1 3348268700 (voice); fax: +1 3348210037 .
} E-mail address: rrummer@ff.fed.us. and the impacts of climate change cast the problem in the broader sense of managing for healthy forests. The Healthy Forest Restoration Act of 2003 set up new authorities to encourage recovery and utilization of biomass from forest health treatments, reduce planning and implementation barriers, and to develop new approaches to resource management.

Under the healthy forest paradigm, millions of acres of forest are candidates for treatment. This is not purely a public lands issue. Non-industrial private forest (NIPF) landowners hold about $58 \%$ of the Nation's timberland (Smith et al., 2004). In addition, the Cohesive Fuels Treatment Strategy (USDA, 2006) emphasizes that priority treatments are in the wildland-urban interface (WUI) where multiple ownerships converge. Increasingly planners realize that addressing landscape-scale resource management for forest health requires coordinated and collaborative action on the part of all forest landowners. Friederici (2006) notes that, although there are political and mechanical constraints on the implementation of landscape-scale forest health treatments, the primary barrier is economic - "someone has to be paid to wield the chainsaws on many, many thousands of acres."

The cost of treatments is a significant barrier and thus it is critical to have a clear understanding of how costs accrue in fuel reduction and forest health treatments. Large-scale assessments such as Cleaves et al. (1996) point out that addressing fuel 
treatments at a national program level requires careful evaluation of costs and benefits to prioritize treatments. Gorte (2006) estimates that current funding levels for fuel reduction are probably orders of magnitude lower than actual need. However, Kline (2004) suggests that there is a lack of reliable quantitative data on which to base cost-benefit analyses of fuel treatment programs. Important analytical studies use assumptions about treatments costs to understand or predict things like forest landowner decisions (Amacher et al., 2005), the effect of fuel treatment on long-term benefit from reduced fire suppression costs (Mason et al., 2003), and the impact of fuel treatments on landowner value (Adams and Latta, 2004). Yet these studies are usually based on a broad single estimate of fuel treatment cost. Winter et al. (2002) observed that personal beliefs about the cost of fuel treatments affect public perception of the acceptability of alternatives. In each of these diverse applications, a sound understanding of the cost of implementing treatments for forest health is critical to reaching valid decisions about public and private investments in resource management.

What is really known about the costs of implementing fuel treatments? The variability of costs is highlighted by anecdotal accounts (e.g. Goad, 2004) of $\$ 200$ per tree for fuel treatment after insect mortality in Southern California. At the other end of the scale are treatments that can return money to the landowner or public through recovery and utilization of products. Costs are obviously affected by a wide range of factors including site conditions, treatment requirements, potential products and markets. A long history of logging cost and production studies provide a foundation, but the unique requirements of fuel reduction and forest health treatments, particularly with the focus on wildland-urban interface operations, cause costs to differ. Answers are not readily available. In fact, the Government Accountability Office $(G A O, 2006)$ points out that the Cohesive Strategy cited previously is still lacking the basic estimate of funding required to accomplish fuel treatment goals. This is due to a lack of reliable estimates on which to base national policy.

The objective of this review is to outline and discuss the various approaches to costing fuel reduction treatments, summarize current knowledge about fuel operations costs and identify critical gaps. Information was collected through literature review. In the ongoing discussion of fuel treatment policy and economics, this review should bring more careful application of the existing literature as well as highlight the need for new data and analyses.

\section{Fuel treatment operations}

One factor that complicates estimates of the cost of fuel treatments is the wide variety of equipment, operations, treatment methods, and stand conditions that may be involved. A brief summary is useful. There are two basic types of fuel reduction treatments - in situ and removal. Removal treatments can be further classified as either removal and disposal or removal and utilization. In situ operations such as prescribed fire, mastication, or manual pile-and-burn achieve fuel objectives by altering the structure of the fuel continuum or by reducing fuel quantity through consumption or accelerated decomposition. When the biomass volume has no utilization potential and fuel objectives can be met with the treated material in the stand, in situ treatment is the least cost alternative.

If there are economically viable utilization opportunities, or if leaving the biomass volume in the stand is unacceptable from a fire risk perspective, some type of removal is required. Taking material from the stand adds cost, particularly if the material form is difficult to collect such as residues or small-diameter trees. Removal can be done manually, by animal logging, forwarding, skidding, or skyline yarding. If the removal treatment includes product recovery, a merchandizing function may be necessary. This step separates product value from residues either in the woods or at roadside. A fuel treatment may achieve the desired outcome with some combination of product removal to extract most of the biomass volume followed by treatment and disposal of residues in the stand. More detailed descriptions of these alternative operations are presented in a previous paper (Rummer, 2004).

The selection of a fuel treatment operation must meet specific fire behavior objectives (Agee and Skinner, 2005). Four key objectives are: 1) reduce surface fuel loading, 2) raise crown base height, 3) reduce canopy bulk density, and 4) retain larger trees of fire-resistant species. Taken together, these objectives restore stand structure that emulates the result of natural fire regimes. In order to achieve these outcomes a fuel reduction operation may have to cut small-diameter non-merchantable material, remove excess biomass volume (fuel loading) from the stand, remove mid-story vegetation, or remove some of the larger overstory. This could require operations as diverse as chainsaw labor, mastication, timber harvesting and skidding, brush treatment, piling and burning, or pruning.

After determining the constraints of a required fuel treatment, the manager must further consider all the operational constraints of a given stand and prescription. This type of constraint may require: equipment that can operate safely on slopes, low-ground pressure operation, restriction of the type of cutting devices, operations on snow or other seasonal requirements. With all of the operational and prescription constraints specified, a subset of possible equipment alternatives can be identified. Cost-benefit analysis can then be used to select a preferred treatment.

It is important to understand that there are differences in objective, method, and outcomes between commercial harvesting and fuel reduction treatments. While a conventional product removal thinning will generally result in reduced stand volumes or other structural changes that are desirable from a wildfire perspective, it may also exacerbate fire risk (Graham et al., 1999). Logging per se can result in additional activity fuels, may decrease surface fuel moisture content, and can increase midflame windspeed - all factors that aggravate wildfire behavior (Scott and Reinhardt, 2001). In addition, commercial harvesting operations are intentionally designed to minimize the cost per unit volume of merchantable timber and may not be optimal for treating other types of vegetation. Thus, conventional logging operations are generally not directly applicable to fuel reduction without some additional operations to address other parts of the fuel spectrum. 


\section{Assessing treatment costs}

The cost of a fuel treatment operation is the sum total of a long list of component costs. These are broadly separated into fixed and variable costs (Riggs, 1977). In engineering cost analysis, there is an implicit boundary that determines the extent of costs considered (Fig. 1). For example, in determining just an operation cost for skidding, the fixed and variable costs of interest may be limited to machine rate and labor values. Determining the total unit production cost requires a larger frame of analysis that combines all sub-operations and considers additional fixed treatment costs. For example, a unit production analysis might compare alternative methods of recovering biomass with stump-to-truck costs expressed as $\$$ per tonne. An even larger frame is necessary, however, to examine questions of profitability or economic feasibility. At this level, all costs of the business must be considered. Stating that an operation is economically feasible without considering all elements in the enterprise frame is meaningless.

The basic costs associated with forest operations are relatively easy to quantify. Machine prices are readily available (Brinker et al., 2002), labor rates can be estimated from sources such as the US Department of Labor, Bureau of Labor Statistics or Davis-Bacon wage determinations for service contract work. Interest rates and fuel prices can also be accurately defined. However, as the analysis frame expands, the costs become harder to assess.

There are direct costs for fuel treatments including project planning and layout, bid preparation, access construction, and performance bonds. A treatment in the wildland-urban interface may incur additional fixed costs that result from local ordinances. Martus et al. (1995) identified 508 local forestry ordinances in the eastern U.S. These require actions such as business and harvest permits, required management plans, bonding, and hauling restrictions in the wildland-urban interface. Other direct costs will include support equipment such as crew transport, fuel or maintenance vehicle, road grader or bulldozer. These cost elements are seldom defined in studies and there is no comprehensive review of their potential magnitude.

\begin{tabular}{|c|c|}
\hline \multicolumn{2}{|c|}{ Enterprise Cost Estimate } \\
\hline \multicolumn{2}{|c|}{ Production Unit Cost Estimate (e.g. \$/acre) } \\
\hline $\begin{array}{l}\text { Operation Cost E } \\
\text { FIXED COSTS } \\
\text { Depreciation } \\
\text { Taxes, Insurance } \\
\text { Labor }\end{array}$ & $\begin{array}{l}\text { stimate (e.g. skidding) } \\
\vdots \text { VARIABLE COSTS } \\
\vdots \text { Fuel } \\
\text { Tires } \\
\text { Repair \& Maintenance }\end{array}$ \\
\hline $\begin{array}{l}\text { Project planning } \\
\text { Permitting } \\
\text { Move-in } \\
\text { Roadwork } \\
\text { Support equipment }\end{array}$ & $\begin{array}{ll} & \text { Landing construction } \\
\vdots & \text { Slash disposal } \\
\vdots & \\
\vdots & \end{array}$ \\
\hline $\begin{array}{l}\text { Office/facilities } \\
\text { Professional fees } \\
\text { Management } \\
\text { Working capital }\end{array}$ & 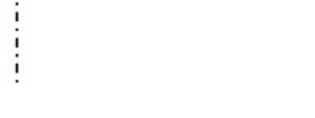 \\
\hline
\end{tabular}

Fig. 1. Different economic analysis frames used to evaluate forest operations.
Some treatments may include requirements for work items in addition to the actual fuel treatment. Such things as best management practice (BMP) implementation, road or trail work, or activity fuel treatment (whether paid in deposits or through work performed) are a form of overhead cost for the fuel treatment. Several studies (Ellefson and Miles, 1985; Lickwar et al., 1992; Shaffer et al., 1998) found that required BMP work on conventional forest harvesting sites in the Midwest and South ranged from negligible to over $25 \%$ of net revenue. The most expensive requirements involved seeding and culvert installations. Some of these costs may be variable at some scales and fixed at others. Landing cost, for example, will be fixed below some optimal treatment unit size for a single landing and variable as unit size increases. Activity fuel treatment could be fixed for burning landing piles or variable depending on volume per acre treated.

Administrative costs and other business overhead are even harder to identify. Stuart et al. (2005) have been tracking cost allocation for conventional logging contractors in the southern US to develop a "logging cost index." They found that about 3\% of total business expenses were strict administrative overhead. Supervisory and support costs were additional and depended on the particular structure of the crew. Lynch (2001) determined that $7 \%$ of total costs for fuel reduction treatments in Colorado were administrative overhead.

Fixed treatment costs are the major contributor to the negative impact of tract size on unit production cost (Greene et al., 1997; Cubbage et al., 1989). Operations with higher capital investment are more sensitive to treatment unit scale (acres or volume treated). All operations experienced sharply increasing unit cost on smaller treatments. The two studies cited above only considered a limited set of overhead costs such as direct moving time and support vehicles. A more complete consideration of total fixed costs would only increase the tract size effect. Berry and Hesseln (2004) found obvious economies of scale for tract size with mechanical fuel treatments. Their analysis of 526 Forest Service and Bureau of Land Management projects also found that costs were higher in the WUI and higher on sensitive sites or slopes.

Studies of timber bid prices also show that a variety of less tangible factors affect the cost of operations. Dahal and Mehmood (2005) developed a bid price model for timber sales in Arkansas. They found, as expected, that factors increasing potential value to the bidder such as amount of sawtimber and accessibility for harvest during winter (when gate price is often higher) increased bid prices. Competition was also a significant factor with more bidders resulting in higher bids. Factors that increased operational costs decreased bid prices, namely selective cutting prescriptions, likely weather delays, and more restrictive contractual provisions. Bids on public land sales were significantly lower. In a similar study, Dunn and Dubois (1999) found that a longer contract period increased bids while additional costs for performance bonds and extra treatment work such as site prep were reflected in lower bids. Kittredge et al. (1996) found loggers in Massachusetts more willing to bid on sales that reduced travel time or were near other jobs to minimize moving costs. Some of these factors 
may be measurable in direct economic terms, others reflect confounded factors that make projects more difficult or complex.

There is also a cost in fuel treatment operations for risk. Projects subject to fire danger shutdown are a simple example. In the western U.S. it is fairly common to expect delays or schedule changes during fire season. There is a certain chance that a project can be completed without delays and there is some other chance that the contractor will be required to move off the job before completion, thus incurring additional expense. There may be other elements of risk in a project. Larson and Mirth (2004) describe a fuel reduction project where the contractor experienced a reduction in market value for pallet logs and the loss of a market for firewood. Lynch and Mackes (2003) describe several fuel reduction treatment projects where contractors had difficulty marketing volume removed. The uncertainty of costs and revenues must be accounted for by incorporating an allowance for risk.

The costs associated with forest operations are varied and complex, leading to different methods for evaluation. There are four basic approaches that have been used to assign a cost to forest operations: 1) expert opinion, 2) transaction evidence, 3) accounting, and 4) engineering cost analysis. Sometimes the total cost for a fuel treatment may be constructed from a combination of these approaches. For example, an engineering analysis of thinning costs may be combined with a transaction evidence cost for slash disposal to estimate total treatment cost. Each approach has advantages and limitations. Keegan et al. (2002) further identify statistical analysis of historical data as a separate method that provides a slightly different classification of cost approaches.

\subsection{The expert opinion method}

The expert opinion method simply asks knowledgeable individuals to estimate cost for a defined operation. It can be structured to poll a particular population, compare costs of alternative scenarios, or even to develop predictive equations for treatment cost as a function of some independent variables.

Keegan et al. (1995) surveyed 25 contractors in Montana to estimate the effect of new harvesting prescriptions on logging costs. They presented a range of detailed prescription scenarios to subjects and asked for estimates of cost $\left(\$\right.$ per $\left.\mathrm{m}^{3}\right)$ for five different cost centers: sale planning and administration, felling, bucking and limbing, skidding or yarding, and loading. Movein costs and postharvest activities were not included. Their logging costs have been cited as the basis for estimating the cost of timber removal in subsequent studies of fuel reduction (e.g., Scott, 1998). Keegan et al. (2002) took the procedure a step further and conducted statistical analysis of expert estimates to develop a prediction equation from another set of treatment scenarios. They found that, in their data, about $63 \%$ of the variation in estimated cost could be explained by average diameter of trees removed, volume per hectare removed, and average skidding distance. Snider et al. (2003) used expert estimates (research scientists) to evaluate the costs and benefits of fuel reduction treatments in southwestern ponderosa pine.
Acknowledging the variation in cost due to site-specific factors, they examined a potential range from $\$ 500$ to $\$ 2000$ per hectare.

Detray et al. (2005) contacted 130 fuels treatment organizations in California, Oregon and Washington operating on small tracts ( $<20$ acres). Based on a response rate of $32 \%$ they found reported costs ranged from $\$ 2350$ to $\$ 4940$ per hectare. The most common type of treatment involved hand crews and small chippers seconded by operations with just manual operations. Nearly three-fourths of the projects had no product removal.

The expert method has two principal advantages over other cost estimating approaches. First, it is relatively quick and inexpensive (Keegan et al., 2002). This is an advantage in collecting local or regional cost estimates (e.g. Mason et al., 2003). Second, it can capture the impact of some intangible costs or restrictions that may not be considered in other cost analysis methods. The estimates are in effect total cost "bids" for the defined work based on the experience of the subjects. Obviously the resolution of the expert method is limited by the degree of detail in the scenario definition. Keegan et al. (1995), for example, defined the stand diameter distribution using average dbh and a range of trees per hectare for both removals and residual. Respondents were thus providing an estimate based on their experience of typical stands. If respondents are asked to estimate costs for treatments outside their range of experience there is also a risk that the expert method will simply be quantifying conventional wisdom and rules-of-thumb.

\subsection{Transaction evidence}

The transaction evidence approach is similar to the expert opinion method in that it represents a total bid cost for a specified operation. It incorporates the effect of competition, some response to all intangible factors of a project, and perhaps some detailed evaluation that may include engineering cost analysis. Berry and Hesseln (2004) used the FASTRACS database, for example, to gather experienced costs for prescribed burning and mechanical fuel treatments. They were able to assemble a database of 586 mechanical fuel treatment projects from a 2-year period. Regression analysis determined that over half of the variation in cost per hectare could be explained by the size of the treatment, whether the treatment occurred in the WUI or a designated protection area, season of operation, fuel type and fire regime, and type of mechanical treatment.

Transaction evidence documents the total cost of operations $e x$ post. This may provide a better estimate of costs than the ex ante expert survey because it reflects what a willing buyer actually exchanged for the service. It most accurately reflects local or regional variables like labor availability and wage rates, and opportunity costs of the contractor pool. However, the converse is also true - transaction evidence data could be worse than other approaches if the bids did not adequately cover expenses and a reasonable return on capital investment. Lynch and Mackes (2003), for example, report on several fuel treatments with removal where the outcome ranged from a $\$ 1230$ per hectare loss to a $4.95 \%$ net profit. Transaction evidence will include poor bid 
preparation. In a competitive market, it also includes intentional underpricing. Some bidders may forego some fixed costs such as depreciation in order to secure a particular contract. Transaction evidence rates also have limited value when they combine product removal and fuel treatment. The reported price is then a lump sum that reflects anticipated market value of products, removal volumes and recovery rates, unique hauling distance costs, and operational costs. When treatments reflect similar conditions, transaction evidence may be a good estimator for projecting costs. However, when treatment conditions vary widely, or the treatment technology is evolving, the transaction evidence approach may have a larger margin of error.

The Central Oregon Intergovernmental Council reviewed information on fuel treatments for possible application in their area (Aycock, 2002). Transaction evidence from a six-year period that preceded the report by only two years found that prescribed fire ranged from $\$ 125$ to $\$ 250$ per hectare, mastication ranged from $\$ 62$ to $\$ 130$ per hectare, and mechanical thinning ranged from $\$ 185$ to $\$ 865$ per hectare. They concluded that “...these figures seem low by today's standards." With little information on the basis of the original transaction costs, it was difficult for the user to extrapolate to new treatments.

\subsection{Accounting method}

The accounting method examines the financial records of a business and allocates total enterprise costs to various accounts such as administration, labor, capital equipment, accounts receivable and contract expenses (Keegan et al., 2002). This type of analysis permits assessment of financial performance through the calculation of measures like return on investment or debt-to-equity ratio. The database is usually total transactions over an accounting period such as a fiscal year or quarter.

Because the accounting method looks at enterprise level financial performance it reflects all of the production activities that occurred during the period. This makes it hard to use the accounting method to evaluate stand level variables or shortterm responses such as seasonal effects.

Accounting studies are rare in forest operations. It is difficult to find willing subjects that have adequate recordkeeping over long study periods. Stuart et al. (2005) have been monitoring a group of over 30 logging contractors in the southern U.S. The accounting data are the basis of the Logging Cost Index, a measure of the relative cost of logging over time with 1995 as the index year. They found that the total cost per ton has risen by $35 \%$ while the Producer Price Index for logging services has declined by $10 \%$ over the same period. The subject population allows comparisons by firm size. The literature review found no reports of an accounting assessment for contractors performing fuel reduction treatments.

\subsection{Engineering cost analysis}

Matthews (1942) defined the foundation of engineering cost analysis applied to forest problems which has remained essentially unchanged in current practice (e.g. FAO, 1992). This approach develops a rate (\$ per hour) for operational functions based on economic analysis of fixed and variable costs. Combined with time-and-motion data defining a production rate (units per hour), a unit production cost can be estimated.

Engineering cost analysis builds a production cost by detailing fixed and variable cost components of an industrial operation that is composed of labor and equipment. Machine rate costing calculates average owning and operating costs over the life of an asset that can be expressed on the basis of a productive hour charge or a scheduled hour charge (Brinker et al., 2002). While some elements of the machine rate, particularly consumables like fuel and cutting tools, can be reliably estimated with short-term recordkeeping and actual expenses; other significant elements like repair and maintenance are based on rule-of-thumb percentages of average capital depreciation. Machine rates are useful for relative comparisons of production options but do not accurately estimate total cost because they do not include tax effects. Burgess and Cubbage (1989) found that machine rates generally exceeded costs estimated on an after-tax cash flow basis. Machine rates are not well-suited to consider the effect of specific business strategies like financing options or purchase of used equipment.

When an operation involves a combination of machines it is also necessary to consider the effect of system balance on production cost. The output of a sequential production process is limited by the capacity of the least productive function. If a system is out of balance and has unused capacity, the fixed costs of under-utilized functions are shared by fewer units of output and per unit production cost rises. For example, a $\$ 500,000$ asset with approximately equal fixed and variable costs would see a $30 \%$ increase in per unit cost if utilization dropped from 90 to $50 \%$ (Fig. 2). For high-level assessment of fuel treatment costs, this effect may be ignored with the assumption that operations will, on average, find some semblance of balance. For tactical project planning, however, system balance is an important consideration since site-specific factors such as tract size, skid distance, equipment selection or hauling distance can create significant imbalance and cost increases.

Unit production cost analyses are the most common approach utilized in studies of fuel reduction. As an example, Hartsough et al. (1997) compared three systems for thinning small-diameter western stands. They used production studies combined with machine rate costs to develop unit production

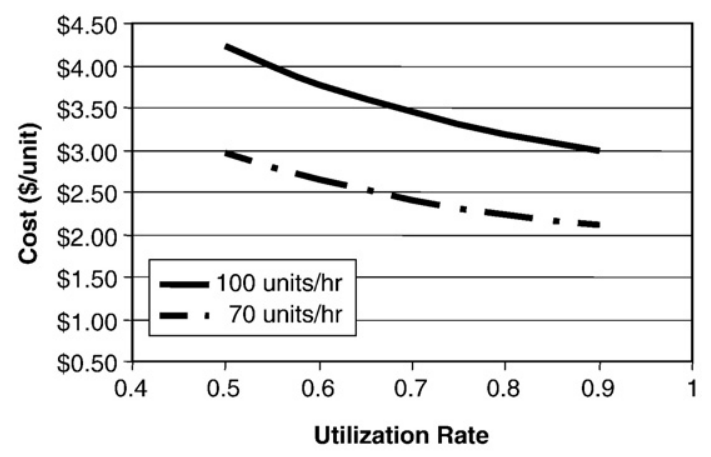

Fig. 2. Effect of utilization rate on unit production cost. 
costs for various products that could be recovered. The study explicitly limited the cost analysis frame to the direct operational costs from stump-to-mill ignoring overhead costs. However, the study design still provided a measure of the relative cost of alternative operations and was able to evaluate opportunities to reduce costs through system modifications.

The engineering cost approach must be used with caution, however, when a study assesses profitability, net revenue, or economic feasibility. Drews et al. (2001), for example, compared two systems for fuel reduction with product removal: a cut-to-length (CTL) harvester with a forwarder and the same harvester using a cable system for yarding. Machine rates, assuming new equipment, were calculated for each system. However, there was no consideration for overhead or profit and risk. Assuming indirect costs affected the two systems equally, it was valid to compare the total costs as a relative measure- the skyline treatment was nearly twice as expensive as the forwarder operation ( $\$ 88$ per green tonne vs. $\$ 50$ ). However, this report also includes a calculation of net revenue based on product value recovered and harvesting costs. This estimate should be qualified since the frame of the harvesting cost analysis was limited.

Brown and Kellogg (1996) document a productivity case study of fuel reduction thinning with a single-grip harvester and a small cable yarder. Using the machine rate method, assuming new equipment and some support costs, they estimated total costs of $\$ 4865$ per hectare and total revenue of $\$ 6375$ per hectare for a net profit of $\$ 1510$ per hectare. Again, the machine rates did not include an allowance for overhead or risk. However, in this study, the authors note that estimated per acre costs were "... similar to the contract rates used in this logging operation." While it is useful to have a reality check on estimated costs, this study may actually be showing that overestimates in machine rates are sufficient to cover overhead costs on actual operations.

Han et al. (2004) evaluated the economic feasibility of harvesting small-diameter trees with recovery of the residues to reduce fire risk. They used a cost analysis program (ST Harvest, Hartsough et al., 2001) to estimate total costs of product removal. Based on local market prices for a range of products they concluded the biomass and clean chip components would be recovered at a net loss while sawlogs were able to return a profit. However, the analysis did not include overhead costs or fixed treatment expenses. Thus, the net economic feasibility of the treatments is in reality unknown.

These examples are not unique in the forest operations literature. Most forest operations field studies set the analysis frame at the machine or stand, rather than the enterprise level. In other words, the fixed and variable costs of machines and operations occurring in the woods are calculated but overhead costs are ignored. Kluender et al. (1995), for example, explicitly defined harvesting profitability as "...the difference between total harvesting costs and the delivered market price..." Their analysis of total costs included machine rates for production functions and stumpage but no allowance for overhead or risk.

Some engineering cost studies have addressed the total cost problem by including some assumption of overhead. Bolding and Lanford (2005), for example, studied a small CTL fuel treatment operation combined with a small chipper for processing biomass. They estimated hourly costs using machine rates, but also included calculation of moving overhead, support, and supervision. Cost analysis was facilitated with the Auburn Harvesting Analyzer (Tufts et al., 1985). Merchantable volume was recovered at a total cost of $\$ 9.37$ per green tonne stump-to-truck while biomass chips cost $\$ 28.27$ per green tonne. Given local market values, the biomass chips were removed at a loss while the product material showed a net profit. Hartsough (2003) assumed a 10\% overhead margin in a study of fuel reduction thinning. Giles and Sessions (1987) assumed $12 \%$ for profit and risk plus administrative costs to assess financial feasibility of thinning stands in southwestern Idaho. Howard (1987), in a study of the profitability of cable skidders, assumed $10 \%$ overhead on operational costs. In addition, in a unique approach to the problem, income tax effects were considered by reducing hourly costs by the product of expenses and the corporate tax rate.

\section{Discussion}

There is clear recognition that better information is needed about the costs of implementing fuel reduction treatments. Critical issues such as national budgets for fire suppression and fuel treatment, policy development to encourage NIPF participation, and market impact assessments rely on accurate estimates of basic costs. The present literature shows a wide range of cost estimates leaving decision-makers with little solid basis for choices.

Part of the uncertainty comes from the range of very different evaluation approaches used in basic studies of operational costs. Obviously each study has specific objectives and scope. Researchers select an analysis method to satisfy the study constraints and avoid unnecessary complexity. However, the cost analysis methods reviewed here have clear differences. It is necessary for studies to clearly identify assumptions and limitations of study methods so users will not draw unwarranted conclusions from results. It is far too easy to cite a cost per hectare from a case study and extrapolate to a regional application. Both researchers and readers bear a responsibility to exercise due diligence and care.

One of the primary issues identified in this review is the range of analysis boundaries in the cited works. Some studies have only included direct costs, others have added some fixed costs such as planning, while still others add an assumption for profit and overhead. Some papers do not clearly state the assumptions used in the cost analysis, making it impossible to compare findings among studies. Because there is so much variability among studies it is doubly important to detail assumptions.

Studies of the economic feasibility of fuel treatments must use total cost numbers. There is no way to determine whether a particular treatment will be profitable if some costs are ignored. Contractors need to be able to make a reasonable profit and cover all of their business costs. Underestimating treatment costs can lead to unreasonable expectations on the part of landowners and 
agencies. Underestimating costs can also encourage efforts to develop marginal wood-using markets which will not be sustainable.

In a similar vein, economic feasibility analyses need reasonably accurate values of actual cost. The basic machine rate approach which is extensively used in forest operations is appropriate for comparative studies. However it has serious limitations when the data are applied to economic feasibility assessments and project estimation. The lack of tax considerations and the use of broad rules-of-thumb for key cost elements like repair and maintenance mean that the actual operating costs are significantly different (likely significantly less). The literature review found very little information on the business cost structure of forest operations contractors. There is no sound basis for assuming profit, risk or overhead rates that will provide this industry with feasible economic performance.

With the recognized limitations of machine rates, transaction evidence studies such as Berry and Hesseln (2004) or expert opinion surveys like Keegan et al. (2002) are likely the best data for regional or national assessments. The costs are actual total costs that integrate many factors. However, authors must keep in mind the limitations of these approaches. Broad surveys do not make good predictors for site-specific projects. In addition, in areas of changing technology like fuel reduction, estimates based on past performance may be suspect.

It is worth mentioning at this point the problem of adjusting data for inflation. Some studies simply state the year of the evaluation and leave adjustments to the reader. Others state that the costs were brought to some common year. Transaction evidence and surveys require an adjustment for inflation since the data is often collected over a period of years. The index for the inflation adjustment should be clearly stated. The Consumer Price Index (CPI) reflects general cost trends in the economy. The Producer Price Index (PPI) more directly measures the cost of industrial goods and services. However, Stuart et al. (2005) have found that the various costs of logging have increased more quickly than either the CPI or PPI. Bringing treatment costs forward using CPI or PPI may lead to an underestimate of current cost.

Finally, basic engineering cost analysis studies are needed to more clearly define productivity functions for the wide variety of new fuel reduction methods. While thinning and removal information is relatively common, treatments like machine piling and slash grinding are less well understood. Such studies are critical to support more robust planning tools like My Fuel Treatment Planner (Biesecker and Fight, 2006).

Cost is a fundamental consideration in forest management. To treat or not to treat. How to treat. Will management be a profitable activity or a cost? In fuel treatment operations the question of cost is highlighted by the marginal potential of product revenue. Treatments that occur at some cost require economic justification. Treatments that can generate revenue need some appraisal to determine a fair economic exchange. The tools of economic analysis that are used today need to be improved. Better tools, applied to a wider range of fuel reduction studies, are needed to provide a solid foundation for fuel reduction policy.

\section{Acknowledgement}

This work was partially supported by funding from the Joint Fire Sciences Program.

\section{References}

Adams, D., Latta, G., 2004. Effects of a forest health thinning program on land and timber values in eastern Oregon. Journal of Forestry 102 (8), 9-13.

Agee, J.K., Skinner, C.N., 2005. Basic principles of forest fuel reduction treatments. Forest Ecology and Management 211 (2005), 83-96.

Amacher, G., Malik, A., Haight, R., 2005. Nonindustrial private landowners, fires, and the wildland-urban interface. Forest Policy and Economics 7 (5), $796-805$.

Aycock, S., 2002. COPWRR strategy framework: reducing wildfire risks in central Oregon by removing and utilizing forest fuels. Central Oregon Intergovernmental Council, Redmond, OR. $121 \mathrm{pp}$.

Berry, A., Hesseln, H., 2004. The effect of the wildland-urban interface on prescribed burning costs in the Pacific Northwestern United States. Journal of Forestry 102 (6), 33-37.

Biesecker, R., Fight, R., 2006. My fuel treatment planner: a users guide. PNW GTR-663. US Department of Agriculture, Forest Service, Pacific Northwest Station, Portland, OR. 31 pp.

Bolding, M.C., Lanford, B.L., 2005. Wildfire fuel harvesting and resultant biomass utilization using a cut-to-length/small chipper system. Forest Products Journal 55 (12), 181-189.

Brinker, R., Kinard, J., Rummer, B., Lanford, B., 2002. Machine rates for selected forest harvesting machines. Circular, vol. 296. Alabama Agricultural Experiment Station, Auburn, AL, p. 29 pp.

Brown, C., Kellogg, L., 1996. Harvesting economics and wood fiber utilization in a fuels reduction project: a case study in eastern Oregon. Forest Products Journal 46 (9), 45-52.

Burgess, J., Cubbage, F., 1989. Comparison of machine rate and cash flow approaches for estimating forest harvesting equipment costs. Paper 89-7548. American Society of Agricultural Engineers, St. Joseph, MI. 24 pp.

Cleaves, D., Schuster, E., Bell, E., 1996. Fire management expenditures by the USDA Forest Service: trends and recommendations for controlling costs. Proceedings of the 1996 Southern Forest Economics Workshop, Gatlinburg, TN, pp. 397-411.

Cubbage, F., Greene, W., Lyon, J., 1989. Tree size and species, stand volume, and tract size: effects on southern harvesting costs. Southern Journal of Applied Forestry 13 (3), 145-152.

Dahal, P., Mehmood, S., 2005. Determinants of timber bid prices in Arkansas. Forest Products Journal 55 (12), 89-94.

Detray, M., Dooley, J., Lanning, D., 2005. Task report: Programs and practices for fuels reduction in the wildland-urban interface. Forest Concepts, Federal Way, WA. <http://www.forestconcepts.com/docs/Survey.1.Summary.pdf > .

Drews, E., Hartsough, B., Doyal, J., Kellogg, L., 2001. Harvester-forwarder and harvester-yarder systems for fuel reduction treatments. Journal of Forest Engineering. 12 (1), 81-87.

Dunn, M., Dubois, M., 1999. Determining economic relationships between timber sale notice provisions and high bids received on timber offerings from the Alabama Department of Conservation/State Lands Division. Timberlands investments: Improving the odds. Proceedings of the 1999 Southern Forest Economics Workshop. Mississippi State University, pp. 83-90.

Ellefson, P., Miles, P., 1985. Protecting water quality in the Midwest: impact on timber harvesting costs. Northern Journal of Applied Forestry 2 (2), 57-61.

Food and Agriculture Organization of the U.N. (FAO), 1992. Cost control in forest harvesting and road construction. Forestry Paper, vol. 99. Food and Agriculture Organization of the United Nations, Rome. $106 \mathrm{pp}$.

Friederici, P., 2006. Some like it hot, some like it culled. Orion 54-61.

Giles, R., Sessions, J., 1987. Harvesting factors affecting financial feasibility of thinning in southwestern Idaho. Western Journal of Applied Forestry. 2 (4), $105-110$.

Goad, B., 2004. Southern California tree removal effort goes into high gear. Press Enterprise, Riverside, CA. 
Gorte, R., 2006. Forest fire/wildfire protection. CRS Report for Congress RL30755. Congressional Research Service, Library of Congress, Washington, DC. 27 pp.

Government Accountability Office (GAO), 2006. Wildland fire management: update on Federal agency efforts to develop a cohesive strategy to address wildland fire threats. GAO-06-617R. Government Accountability Office, Washington, DC. 19 pp.

Graham, R., Harvey, A., Jain, T., Tonn, J., 1999. The effects of thinning and similar stand treatments on fire behavior in western forests. PNW GTR-463. US Department of Agriculture, Forest Service, Pacific Northwest Research Station, Portland, OR. 27 pp.

Greene, W., Harris, T., DeForest, C., Wang, J., 1997. Harvesting cost implications of changes in the size of timber sales in Georgia. Southern Journal of Applied Forestry 21 (4), 193-198.

Han, H.-S., Lee, H., Johnson, L., 2004. Economic feasibility of an integrated harvesting system for small-diameter trees in southwest Idaho. Forest Products Journal 54 (2), 21-27.

Hartsough, B., 2003. Economics of harvesting to maintain high structural diversity and resulting damage to residual trees. Western Journal of Applied Forestry 18 (2), 133-142.

Hartsough, B., Drews, E., McNeel, J., Durston, T., Stokes, B., 1997. Comparison of mechanized systems for thinning ponderosa pine and mixed conifer stands. Forest Products Journal 47 (11/12), 59-68.

Hartsough, B., Zhang, X., Fight, R., 2001. Harvesting cost model for small trees in natural stands in the Interior Northwest. Forest Products Journal 51 (4), 54-61.

Howard, A., 1987. Modeling the cost and profitability of timber harvesting with cable skidders. Northern Journal of Applied Forestry 4 (2), 87-92.

Keegan, C., Fiedler, C., Stewart, F., 1995. Cost of timber harvest under traditional and "new forestry" silvicultural prescriptions. Western Journal of Applied Forestry 10 (1), 36-42.

Keegan, C., Niccolucci, M., Fiedler, C., Jones, J., Regel, R., 2002. Harvest cost collection approaches and associated equations for restoration treatments on national forests. Forest Products Journal 52 (7/8), 96-99.

Kittredge, D., Mauri, M., McGuire, E., 1996. Decreasing woodlot size and the future of timber sales in Massachusetts: when is an operation too small? Northern Journal of Applied Forestry 13 (2), 96-101.

Kline, J., 2004. Issues in evaluating the costs and benefits of fuel treatments to reduce wildfire in the Nation's forests. Research Note PNW-RN-542. U.S. Department of Agriculture, Pacific Northwest Research Station, Portland, OR. 47 pp.

Kluender, R., Lortz, D., McCoy, W., 1995. Harvesting profitability variability by removal intensity and tree size. Proceedings of the 1995 Council on Forest Engineering Meeting. Corvallis, OR, COFE.

Larson, D., Mirth, R., 2004. A case study on the economics of thinning in the wildland urban interface. Western Journal of Applied Forestry 19 (1), 60-65.

Lickwar, P., Hickman, C., Cubbage, F., 1992. Costs of protecting water quality during harvesting on private forestlands in the Southeast. Southern Journal of Applied Forestry 16 (1), 13-20.
Lynch, D., 2001. Financial results of ponderosa pine forest restoration in southwestern Colorado. Ponderosa pine ecosystems conservation and restoration: Steps toward stewardship. Proceedings RMRS-P-22. US Department of Agriculture, Forest Service, Rocky Mountain Research Station, Ft. Collins, CO, pp. 141-148.

Lynch, D., Mackes, K., 2003. Costs for reducing fuels in Colorado fores restoration projects. Fire, Fuel Treatments, and Ecological Restoration. Proceedings RMRS-P-29. US Department of Agriculture, Forest Service, Rocky Mountain Research Station, Ft. Collins, CO, pp. 167-175.

Martus, C., Haney, H., Siegel, W., 1995. Local forest regulatory ordinances. Journal of Forestry 93 (6), 27-31.

Mason, C., Ceder, K., Rogers, H., Bloxton, T., Comnick, J., Lippke, B., McCarter, J., Zobrist, K., 2003. Investigation of alternative strategies for design, layout and administration of fuel removal projects. Rural Technology Initiative Report. University of Washington, Seattle, WA. 78 pp.

Matthews, D., 1942. Cost control in the logging industry. McGraw Hill, New York

Riggs, J., 1977. Engineering economics. McGraw Hill, New York.

Rummer, B., 2004. Technology for treating fuels and small-diameter material. One Forest Under Two Flags. Proceedings of the 2004 SAF National Convention. Society of American Foresters, Bethesda, MD.

Scott, J., 1998. Fuel reduction in residential and scenic forests: a comparison of three treatments in a western Montana ponderosa pine stand. Res Paper RMRS-RP-5. U.S. Department of Agriculture, Forest Service, Rocky Mountain Research Station, Odgen, UT. 19 pp.

Scott, J.H., Reinhardt, E.D., 2001. Assessing crown fire potential by linking models of surface and crown fire behavior. Research Paper RMRS-RP-29. US Department of Agriculture, Forest Service, Rocky Mountain Research Station, Ft. Collins, CO.

Shaffer, R., Haney, H., Worrell, E., Aust, W., 1998. Forestry BMP implementation costs for Virginia. Forest Products Journal 48 (9), 27-29.

Smith, W., Miles, P., Vissage, J., Pugh, S., 2004. Forest resources of the United States, 2002. Gen Tech Report NC-241. US Department of Agriculture, Forest Service, North Central Research Station, St. Paul, MN, p. 137 pp.

Snider, G., Wood, D., Daugherty, P., 2003. Analysis of costs and benefits of restoration-based hazardous fuel reduction. Treatments vs. no treatment Progress Report, vol. 1. Northern Arizona University, Forestry, Flagstaff, AZ. 14 pp.

Stuart, W., Grace, L., Altizer, C., 2005. Final 2003 logging cost indices. FWRC \#FO-439. Mississippi State University, Forest and Wildlife Research Center, Starkville, MS. 12 pp.

Tufts, R., Lanford, B., Greene, W., Burrows, J., 1985. Auburn harvesting analyzer. Compiler 3 (2), 14-15.

USDA/DOI, 2006. Protecting people and natural resources. A cohesive fuels treatment strategy. US Department of Agriculture, Washington, DC. 60 pp.

Winter, G., Vogt, C., Fried, J., 2002. Fuel treatments at the wildland-urban interface. Common concerns in diverse regions. Journal of Forestry 100 (1), $15-21$. 